\title{
Modelagem espacial da erosão hídrica do solo associada à sazonalidade agroclimática na região sul do Rio Grande do Sul, Brasil
}

\author{
Spatial modeling of soil water erosion associated with agroclimatic \\ seasonality in the southern region of Rio Grande do Sul, Brazil
}

\begin{abstract}
Stefan Domingues Nachtigall ${ }^{*}{ }^{\oplus}$, Maria Cândida Moitinho Nunes ${ }^{1} \odot$, Jean Michel Moura-Bueno ${ }^{2} \odot$, Cláudia Liane Rodrigues de Lima' ${ }^{\oplus}$, Pablo Miguel ${ }^{\circledR}$, Samuel Beskow ${ }^{3} \odot$, Thais Palumbo Silva² ${ }^{\circ}$
\end{abstract}

$\square$

\begin{abstract}
RESUMO
A erosão hídrica constitui um sério problema de degradação do solo, com impacto em diversas áreas. Sua mensuração é de extrema importância e onerosa. Os modelos empíricos de estimativa de perdas de solo, como a Equação Universal de Perda de Solo Revisada (RUSLE), são utilizados para suprir essa demanda. Consideram-se poucos estudos no Brasil que avaliam o efeito da sazonalidade agroclimática nas estimativas de perda de solo por erosão hídrica em bacias hidrográficas. Dessa forma, o objetivo deste estudo foi avaliar a sazonalidade agroclimática na estimativa de perdas de solo por meio da RUSLE e identificar os fatores que controlam a erosão na Bacia Hidrográfica do Arroio Fragata (BHAF). O fator erosividade da chuva (R) e a média anual de precipitação foram calculados por meio de dados de quatro estações pluviométricas.. O fator erodibilidade do solo (K) foi obtido a partir de informações de solo. O fator topográfico (LS) foi gerado com base no modelo digital de elevação (MDE) e o fator cobertura do solo e práticas conservacionistas (CP) por meio de imagens do satélite Landsat8/ OLI. A variação sazonal teve efeito na perda de solo, com maiores taxas de erosão no período de verão e primavera. Perdas de solo entre 5 e $50 \mathrm{Mg} \mathrm{ha}^{-1} \mathrm{ano}^{-1}$ foram registradas em $24 \%$ da BHAF, associadas a períodos de chuvas mais erosivas, maior declividade e baixa cobertura vegetal. Os fatores da RUSLE com maior contribuição na erosão foram R, LS e CP. A abordagem apresentada pode ser útil para quantificar as perdas de solo em bacias hidrográficas.
\end{abstract}

Palavras-chave: geoprocessamento; equação universal de perda de solo revisada; variabilidade sazonal; perdas de solo; conservação do solo.

\begin{abstract}
Water erosion is a serious soil degradation problem, with impact in several areas. Its measurement is extremely important and costly. Empirical models of soil loss estimation, such as the revised universal soil Ioss equation (RUSLE), are used to meet this demand. Few studies in Brazil are considered to evaluate the effect on agroclimatic seasonality in the estimates of soil loss due to water erosion in watersheds. Thus, the objective of this study was to evaluate the agroclimatic seasonality in the estimation of soil losses through RUSLE and to identify the factors that control erosion in the watershed of the Fragata stream. Rainfall erosivity (R) was calculated by means of precipitation data for four seasons and annual average. The soil erodibility factor (K) was obtained from soil information. The topographic factor (LS) was generated from the Digital Elevation Model (MDE) and the soil cover factor and conservationist practices (CP) through Landsat8/OLI satellite images. Seasonal variation had an effect on soil loss, with higher erosion rates in the summer and spring months. Soil losses between 5 and 50 Mg ha'ano-1 were recorded in 24\% of the BHAF, associated with periods of more erosive rainfall, higher slope and low vegetation cover. RUSLE factors with the greatest contribution to erosion were R, LS, and CP. The approach presented can be useful in quantifying soil losses in river basins.
\end{abstract}

Keywords: geoprocessing; revised universal soil loss equation; seasonal variability; soil loss; soil conservation.

\section{INTRODUÇÃO}

A erosão do solo é um problema encontrado em diversas sociedades que necessitam da agricultura, e essa problemática se agrava quando as taxas naturais de perda de solo aumentam em razão das atividades antrópicas (DOTTERWEICH, 2013). Segundo o relatório apresentado pela Organização das Nações Unidas para Alimentação e Agricultura (FAO, 2017), 33\% dos solos do mundo estão degradados por diversos fatores, entre eles, o processo erosivo acelerado. Esse processo, se não

'Programa de Pós-Graduação em Manejo e Conservação do Solo e da Água, Universidade Federal de Pelotas - Pelotas (RS), Brasil.

2Programa de Pós-Graduação em Ciência do Solo, Universidade Federal de Santa Maria - Santa Maria (RS), Brasil.

${ }^{3}$ Centro de Desenvolvimento Tecnológico, Programa de Pós-Graduação em Recursos Hídricos, Universidade Federal de Pelotas - Pelotas (RS), Brasil.

*Autor correspondente: stefan.nachtigall@ufpel.edu.br

Recebido: 30/04/2019 - Aceito: 04/03/2020 - Reg. Abes: 20190136 
controlado, pode impactar na profundidade e na capacidade produtiva, acelerar o transporte de agroquímicos e partículas do solo para corpos d'água e modificar a capacidade de fluxo de água e sedimento nos rios (DOTTERWEICH, 2013; DI STEFANO; FERRO, 2016; OCHOA et al., 2016; WANG et al., 2016; ANACHE et al., 2017; PANAGOS et al., 2017). Adicionalmente, pode reduzir o potencial que o solo possui em sequestrar carbono (FAO, 2017; LAL et al., 2018).

No Brasil, a erosão causada pela água da chuva é a forma mais significativa de degradação do solo, com estimativa do volume de solo perdido variando de 0,1 a $136,0 \mathrm{t} \mathrm{ha}^{-1}$, conforme o uso e a cobertura da terra (ANACHE et al., 2017). No estado do Rio Grande do Sul (RS), o processo erosivo acelerado, principalmente em áreas de lavoura, é decorrente do manejo inadequado e da ausência de práticas conservacionistas (MIGUEL et al., 2014; TIECHER et al., 2017). Nessa região, o maior impacto do processo erosivo é observado em áreas de lavoura sob relevo declivoso e com ausência de cobertura (DIDONÉ et al., 2014; MOURA-BUENO et al., 2018).

O mapeamento detalhado do processo erosivo e a caracterização da extensão e da magnitude das taxas anuais e sazonais de erosão do solo em escala regional se tornam ferramenta imprescindível para a definição de práticas conservacionistas (BESKOW et al., 2009; FERREIRA; PANAGOPOULOS, 2014; ANACHE et al., 2017; GAUBI et al., 2017; COUTO JÚNIOR et al., 2019). Nesse sentido, a avaliação das perdas de solo em bacias hidrográficas, associada à sazonalidade agroclimática, possibilita a realização de um diagnóstico ambiental da área (TIECHER et al., 2017), em que todos os fatores que interferem no processo erosivo sejam avaliados com o propósito de compreender as interações em escala de bacia hidrográfica e definir ações conservacionistas (GAUBI et al., 2017).

Modelos empíricos, como a Equação Universal de Perda de Solo (USLE) (WISCHMEIER; SMITH, 1978) e sua versão revisada, RUSLE (RENARD et al., 1997), são utilizados mundialmente para estimar a perda de solo (FERREIRA; PANAGOPOULOS, 2014; BATISTA et al., 2017; MONDAL; KHARE; KUNDU, 2018; COUTO JÚNIOR et al., 2019). Esses modelos utilizam informações do meio físico para estimar a erosão, geralmente, em escala de bacia hidrográfica. A perda anual de solo é estimada a partir da combinação de seis fatores contidos na RUSLE: erosividade da chuva (R), erodibilidade do solo (K), fator topográfico (LS), uso e manejo do solo (C) e práticas conservacionistas $(\mathrm{P})$. Os fatores $\mathrm{R}, \mathrm{LS}, \mathrm{C}$ e $\mathrm{P}$ têm mostrado ter influência na magnitude do processo erosivo no Brasil (DIDONÉ et al., 2014; GAUBI et al., 2017; BARROS et al., 2018) e no mundo (WANG et al., 2016; PANAGOS et al., 2017).

No Brasil, a sazonalidade das atividades de preparo do solo, semeadura e colheita das culturas está relacionada com o zoneamento agroclimático dos estados. Isso tem influência direta no período em que o solo permanece exposto e vulnerável aos agentes erosivos (CARVALHO et al., 2014; GRAÇA et al., 2015). A variação climática afeta condições específicas no solo, tais como a umidade e a temperatura, refletindo na taxa de infiltração de água, na ciclagem de nutrientes e no desenvolvimento das plantas, no percentual de cobertura (TURMEL et al., 2015) e nas taxas de perda de solo (CARVALHO et al., 2014).

O efeito da sazonalidade na perda de solo foi avaliado por Prado e Nóbrega (2005) em uma bacia hidrográfica do córrego Ipiranga no estado do Paraná, onde foi observado que é possível identificar os períodos do ano mais críticos para ocorrência do processo erosivo. Períodos com maior erosividade das chuvas e menor cobertura do solo foram correlacionados com as maiores perdas de solo em uma bacia hidrográfica no Mediterrâneo (FERREIRA; PANAGOPOULOS, 2014). Os autores concluíram que é possível determinar os períodos do ano e a localização das áreas mais suscetíveis ao processo erosivo com maior precisão. Variações na erosividade das chuvas também foram observadas por Batista et al. (2017) em uma bacia hidrográfica no estado de Minas Gerais. Essas variações afetam diretamente a variabilidade das perdas de solo na paisagem (BOIX-FAYOS et al., 2006), indicando a necessidade dos monitoramentos local e regional desse fator para fins de modelagem das perdas de solo por erosão hídrica.

De maneira análoga, a variação no uso da terra no decorrer do ano promove alterações na rugosidade e na porcentagem de cobertura do solo. Tal variações influenciam nas estimativas de perdas de solo (BOIXFAYOS et al., 2006; EVRARD et al., 2010; CARVALHO et al., 2014), principalmente em áreas com relevo declivoso (ZHOU et al., 2008; MOURA-BUENO et al., 2018). Para entender as interações entre os fatores relacionados ao processo erosivo, Oliveira, Wendland e Nearing (2013) e Anache et al. (2017) apontam a necessidade de avaliações contínuas em todo o território brasileiro, ressaltando a importância do uso de modelos mais flexíveis (integração de fatores) para predição da erosão, principalmente em regiões onde há escassez de dados de perda de solo. Além disso, existe uma carência de estudos que avaliam o efeito da sazonalidade nas estimativas de perda de solo por erosão hídrica em bacias hidrográficas, com destaque para a Região Sul do Brasil, onde existe alta variação climática ao longo no ano (OLIVEIRA; WENDLAND; NEARING, 2012; CERA; FERRAZ, 2015).

Dessa forma, foi levantada a hipótese de que a sazonalidade, associada a fatores relacionados a cobertura do solo e relevo, tem atuação significativa na magnitude das taxas de erosão em uma bacia hidrográfica. Assim, o objetivo deste estudo foi compreender o comportamento da sazonalidade agroclimática na estimativa de perda de solo, por meio da RUSLE, e identificar os fatores que controlam o processo erosivo na Bacia Hidrográfica do Arroio Fragata (BHAF), na região sul do RS. Nesse sentido, o artigo buscou mostrar uma nova abordagem por meio da integração entre as dinâmicas espacial e temporal dos fatores relacionados ao processo erosivo expressos no modelo RUSLE, visando que esse modelo se torne melhor adaptado para comtemplar as diversas condições espaciais e locais que regulam diferentes bacias hidrográficas. 


\section{METODOLOGIA}

O estudo foi realizado na BHAF, a qual abrange uma área de aproximadamente $225,30 \mathrm{~km}^{2}$, localizada entre as longitudes $-52^{\circ} 40^{\prime}$ e $-52^{\circ} 20^{\prime}$ e as latitudes $-31^{\circ} 50^{\prime}$ e $-31^{\circ} 35^{\prime}$ da região sul do estado do RS, Brasil (Figura 1). Os usos da terra na bacia são: pastagem/campo $(46,09 \%)$, floresta $(25,59 \%)$, solo exposto $(13,53 \%)$, agricultura $(9,18 \%)$, área urbana $(4,21 \%)$, água $(1,21 \%)$ e área industrial $(0,18 \%)$. O clima da região, segundo a classificação de Köppen, é Cfa, subtropical úmido com verão quente (ALVARES et al., 2013). A média anual de precipitação é de 1.385,6 mm (SANTOS, 2013).

Com base no modelo digital de elevação (MDE) disponibilizado pelo Shuttle Radar Topography Mission (SRTM) (FARR et al., 2007), na resolução espacial de $30 \mathrm{~m}$, foi obtida a altimetria da bacia, a qual varia de 0 a $350 \mathrm{~m}$. A altimetria foi utilizada para gerar as informações de fluxo acumulado e direção do fluxo por meio da geração de grades de processos hidrológicos no sistema de informações geográficas (SIG) SPRING elaborado por Câmara et al. (1996).

O mapa de solos da BHAF (Figura 2) foi obtido da compilação do mapeamento de solos dos municípios de Capão do Leão (CUNHA; SILVEIRA, 1996a), Pelotas (CUNHA; SILVEIRA, 1996b) e Morro Redondo (CUNHA; SILVEIRA; SEVERO, 1996). Capão do Leão e Morro Redondo possuem mapas em escala de 1:50.000 e Pelotas, de 1:100.000. As classes de solos foram atualizadas para a $5^{\text {a }}$ edição do Sistema Brasileiro de Classificação de Solos (SANTOS et al., 2018).

De acordo com os mapeamentos, a BHAF possui: 10,85\% de Argissolo Bruno-Acinzentado Distrófico (PBACd); 0,63\% de Neossolo Regolítico Distrófico (RRd); 3,53\% de Argissolo Vermelho-Amarelo
Distrófico (PVAd); 31,54\% do Planossolo Háplico Eutrófico (SXe); 5,16\% do Gleissolo Melânico Ta Eutrófico (GMve); 4,34\% de Espodossolo Ferri-Humilúvico Órtico (ESKo); 11,49\% da associação PBACd + RRd + RRe (Neossolo Regolítico Eutrófico - RRe); 2,44\% de RRd + PBACd; 23,94\% de PVAd + PVAe (Argissolo Vermelho-Amarelo Eutrófico PVAe); e 6,08\% de GMve+OX (Organossolo Háplico - OX).

Para estimar a erosão do solo, foi utilizado o modelo empírico RUSLE proposto por Renard et al. (1997). O modelo baseia-se na multiplicação de seis fatores para estimar a erosão do solo por unidade de área (Equação 1).

\section{$A=R \times K \times L S \times C \times P$}

Em que:

$\mathrm{A}=$ perda de solo por unidade de área $\left(\mathrm{Mg} \mathrm{ha}^{-1} \mathrm{ano}^{-1}\right)$;

$\mathrm{R}=$ índice de erosividade $\left(\mathrm{MJ} \mathrm{mm} \mathrm{ha} \mathrm{m}^{-1} \mathrm{~h}^{-1} \mathrm{ano}^{-1}\right)$;

$\mathrm{K}$ = fator de erodibilidade do solo: intensidade de erosão por unidade de área para um solo específico que é mantido continuamente sem cobertura, com intervenções culturais normais, em uma declividade de $9 \%$ e comprimento de rampa de $22,1 \mathrm{~m}\left(\mathrm{Mg}\right.$ ha h $\left.\mathrm{MJ}^{-1} \mathrm{~mm}^{-1} \mathrm{ha}^{-1}\right)$; $\mathrm{L}=$ fator comprimento de declive: relação de perdas de solo entre um comprimento de declive qualquer e um de 22,1 m para as mesmas condições e grau de declive (adimensional);

$\mathrm{S}$ = fator grau de declive: relação de perdas de solo entre um declive qualquer e uma declividade de $9 \%$ para as mesmas condições (adimensional); $\mathrm{C}=$ fator de uso e manejo: relação entre perdas de solo de um terreno cultivado em dadas condições e as perdas correspondentes de um

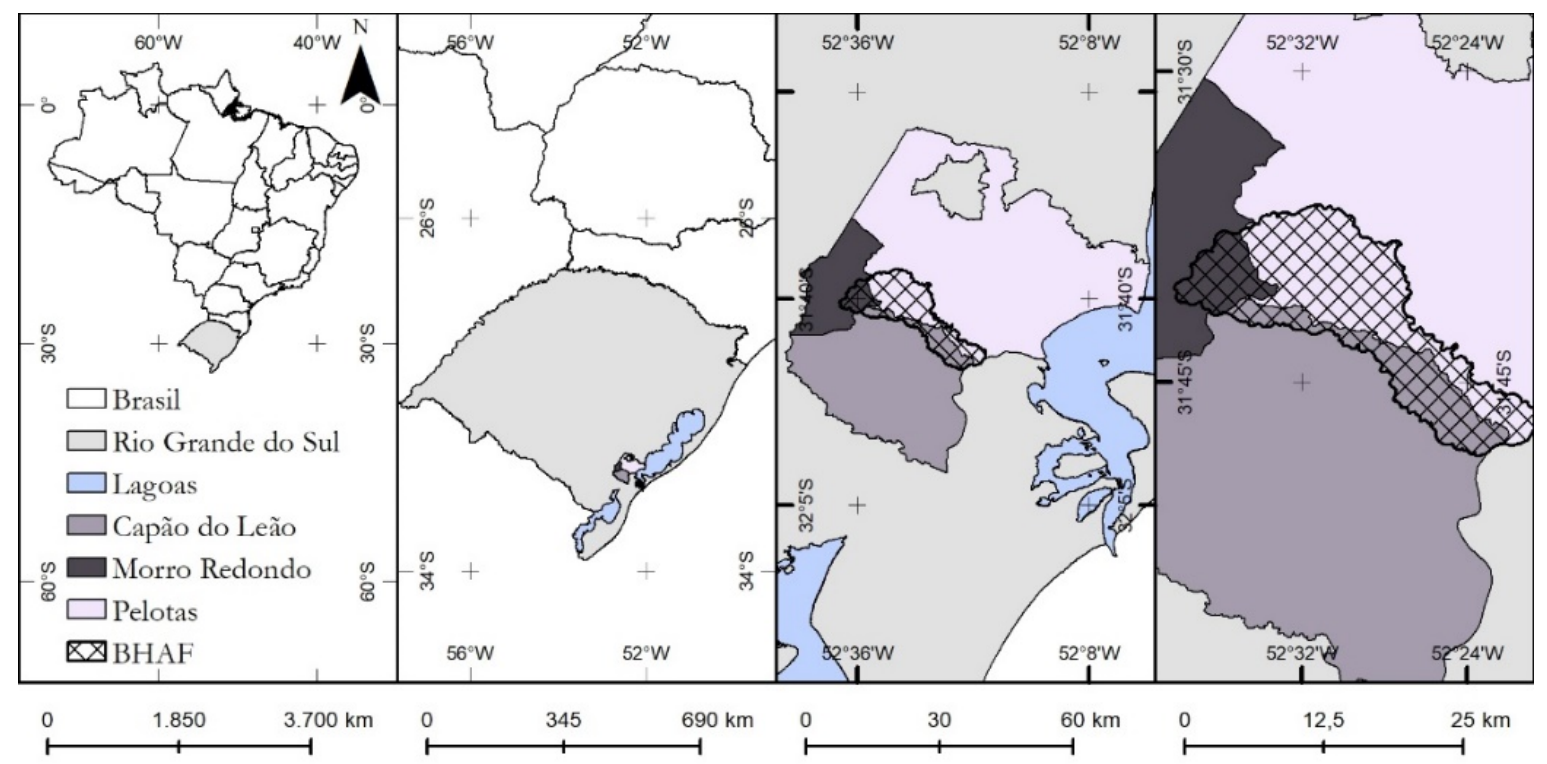

BHAF: Bacia Hidrográfica do Arroio Fragata.

Figura 1 - Mapa de localização da Bacia Hidrográfica do Arroio Fragata no sul do estado do Rio Grande do Sul, Brasil. 
terreno mantido continuamente descoberto, isto é, nas mesmas condições que o fator K é avaliado (adimensional);

$\mathrm{P}=$ fator prática conservacionista, o qual varia entre 0 e 1 , em que 1 representa a ausência de práticas de controle do processo erosivo.

O conjunto de dados utilizados para o cálculo do fator R foi obtido por Santos (2013). Esses dados são espacializados para cada mês do ano, o que possibilitou considerar a sazonalidade climática, em que os meses foram agrupados com base nas estações (verão, outono, inverno e primavera), formando uma escala temporal para a precipitação erosiva ao longo do ano.

Os dados do fator $\mathrm{R}$ variam de 7.418,5 a 8.999,3 $\mathrm{MJ} \mathrm{mm} \mathrm{ha-1} \mathrm{h}^{-1}$ ano $^{-1}$, com média anual de $8.208,9 \mathrm{MJ} \mathrm{mm} \mathrm{ha}^{-1} \mathrm{~h}^{-1}$ ano $^{-1}$. Esses valores são próximos aos observados por Oliveira, Wendland e Nearing (2012) e Trindade et al. (2016), que evidenciaram erosividade entre $6.000 \mathrm{e}$ 8.000 MJ mm ha-1 $\mathrm{h}^{-1}$ ano $^{-1}$ para a Região Sul do Brasil.

As chuvas do período de verão apresentaram o maior potencial erosivo médio e a menor amplitude (Tabela 1), o que as caracteriza como chuvas de erosividade homogênea. As chuvas da primavera possuem a menor erosividade média e a maior variação (Tabela 1), com potencial erosivo heterogêneo. Geralmente, as chuvas com maior potencial erosivo no território brasileiro se concentram nos períodos do verão e da primavera (OLIVEIRA; WENDLAND; NEARING, 2013). Contudo, na Região Sul do Brasil, onde predomina o clima subtropical, há chuvas mais erosivas nos períodos do verão e do outono (OLIVEIRA; WENDLAND; NEARING, 2013), corroborando os dados apresentados na Tabela 1.

O fator K para cada classe de solo da BHAF foi calculado a partir de informações dos perfis de solo de Cunha e Silveira (1996a; 1996b) e Cunha, Silveira e Severo (1996). Três métodos para estimar o fator $\mathrm{K}$ foram utilizados, com o objetivo de avaliar a variação dos valores para a área de estudo:

Tabela 1 - Valores mínimos, médios, máximos e amplitude da erosividade da chuva.

\begin{tabular}{l|c|c|c|c}
\multirow{2}{*}{ Período } & \multicolumn{4}{|c}{ Erosividade da chuva } \\
\cline { 2 - 5 } & Mínimo & $\begin{array}{c}\text { Média do } \\
\text { período }\end{array}$ & Máximo & Amplitude \\
\cline { 2 - 5 } Verão & $2.118,3$ & $2.192,4$ & $2.256,9$ & 129,0 \\
\hline Outono & $1.947,6$ & $2.118,9$ & $2.290,3$ & 342,7 \\
\hline Inverno & $1.721,7$ & $1.979,4$ & $2.237,1$ & 515,4 \\
\hline Primavera & $1.625,0$ & $1.905,6$ & $2.186,2$ & 561,2 \\
\hline
\end{tabular}

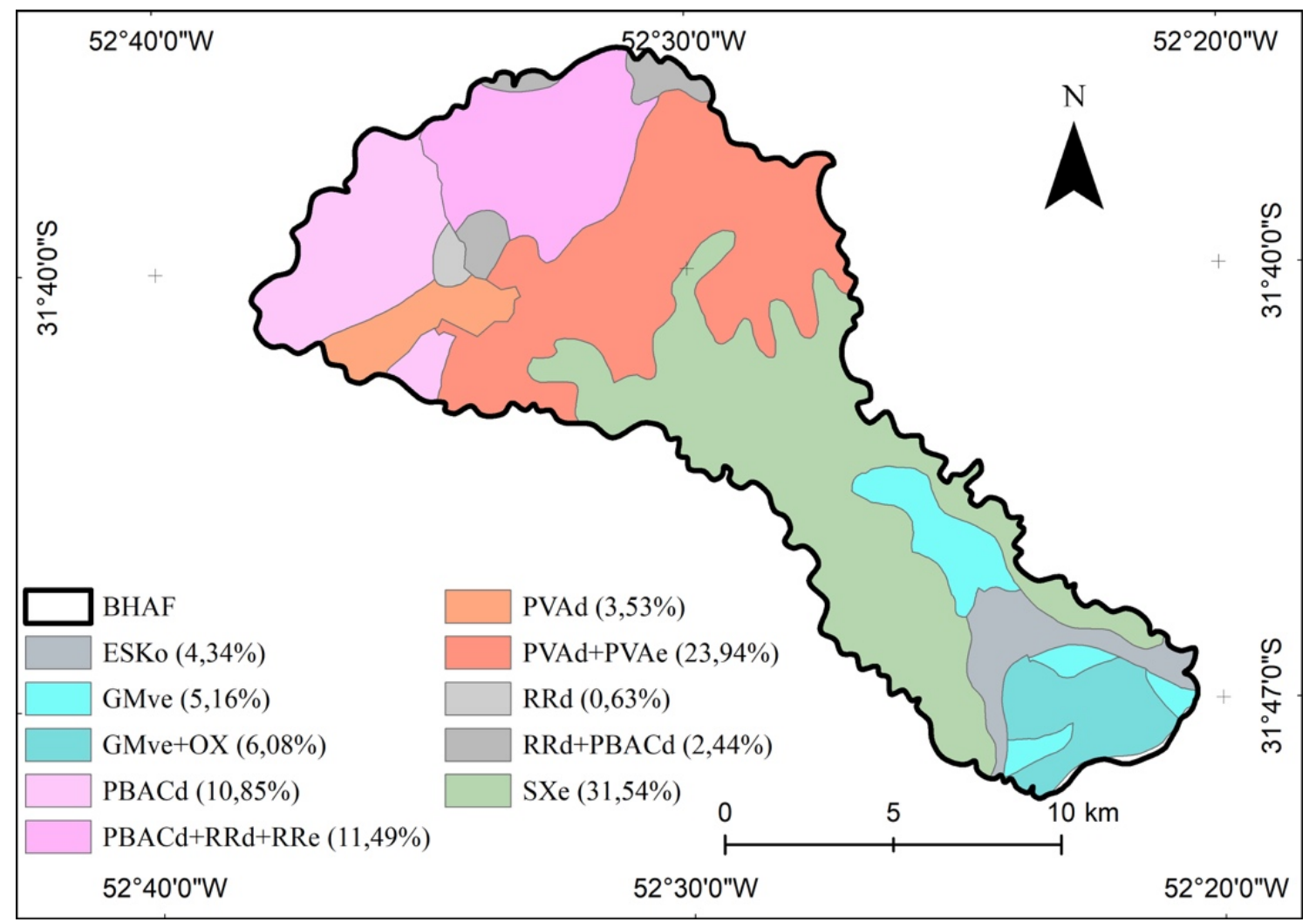

ESKo: Espodossolo Ferri-Humilúvico Órtico; GMve: Gleissolo Melânico Ta Eutrófico; GMve + OX: Gleissolo Melânico Ta Eutrófico + Organossolo Háplico; PBACd: Argissolo Bruno-Acinzentado Distrófico; PBACd + RRd + RRe: Argissolo Bruno-Acinzentado Distrófico + Neossolo Regolítico Distrófico + Neossolo Regolítico Eutrófico; PVAd: Argissolo Vermelho-Amarelo Distrófico; PVAd + PVAe: Argissolo Vermelho-Amarelo Distrófico + Argissolo Vermelho-Amarelo Eutrófico; RRd: Neossolo Regolítico Distrófico; RRd + PBACd: Neossolo Regolítico Distrófico + Argissolo Bruno-Acinzentado Distrófico; SXe: Planossolo Háplico Eutrófico; BHAF: Bacia Hidrográfica do Arroio Fragata.

Figura 2 - Mapa de classes de solos da Bacia Hidrográfica do Arroio Fragata com suas respectivas áreas relativas. 
- Método 1: equação baseada em atributos físicos e químicos de solos do Brasil e dos Estados Unidos (DENARDIN, 1990) (Equação 2);

- Método 2: equação baseada em atributos físicos e químicos para solos do Brasil (DENARDIN, 1990) (Equação 3);

- Método 3: equação proposta por Wischmeier, Johnson e Cross (1971), que considera teor de matéria orgânica, textura, estrutura e permeabilidade do solo (Equação 4).

$\mathrm{K}=0,00608397(\mathrm{P} 1)+0,00834285(\mathrm{P} 2)-0,00116162(\mathrm{P} 3)-0,00037756(\mathrm{P} 4)$

Em que:

$\mathrm{K}=$ erodibilidade do solo estimada $\left(\mathrm{Mg}\right.$ ha h $\left.\mathrm{MJ}^{-1} \mathrm{~mm}^{-1} \mathrm{ha}^{-1}\right)$;

$\mathrm{P} 1$ = permeabilidade do perfil, conforme Wischmeier, Johnson e

Cross (1971);

P2 = teor de matéria orgânica (\%);

P3 = teor de óxido de alumínio extraível por ácido sulfúrico (\%);

P4 = teor de partículas com diâmetro entre 2,0 e 0,5 mm, determinados pelo método da pipeta (\%).

$\mathrm{K}=0,00000748(X 1)+0,00448059(X 2)-0,06311750(X 3)+0,01039567(X 4)$

Em que:

$\mathrm{K}=$ erodibilidade do solo estimada $\left(\mathrm{Mg}\right.$ ha h $\left.\mathrm{MJ}^{-1} \mathrm{~mm}^{-1} \mathrm{ha}^{-1}\right)$;

$\mathrm{X} 1=(\%$ silte $+\%$ areia muito fina $) *(100-\%$ argila $) ;$

$\mathrm{X} 2$ = permeabilidade do perfil do solo, conforme Wischmeier, Johnson e Cross (1971);

$\mathrm{X} 3$ = diâmetro médio ponderado $(\mathrm{DMP})$ das partículas $<2,0 \mathrm{~mm}$, calculado pela seguinte equação: $\mathrm{DMP}=\sum\left(\mathrm{Ci}{ }^{\star} \mathrm{Pi}\right)$, em que:

$\mathrm{Ci}=$ centro da classe textural $\mathrm{i}$, expresso em $\mathrm{mm}$;

$\mathrm{Pi}=$ proporção de ocorrência da classe textural i, expressa em \%;

$\mathrm{X} 4=(\% \mathrm{MO} / \%$ areia total $-\%$ areia muito fina $)$, em que:

$\% \mathrm{MO}=$ valor da matéria orgânica em \%.

$K=1,451 \times 10^{-10} \cdot(120-M O) \cdot M^{1,14}+0,0043(S 1)+0,0033(P)$

Em que:

$\mathrm{K}=$ erodibilidade do solo estimada $\left(\mathrm{Mg}\right.$ ha h $\left.\mathrm{MJ}^{-1} \mathrm{~mm}^{-1} \mathrm{ha}^{-1}\right)$;

$\mathrm{MO}=$ teor de matéria orgânica $\left(\mathrm{g} \mathrm{kg}^{-1}\right)$;

$\mathrm{M}=$ soma de areia muito fina $\left(\mathrm{g} \mathrm{kg}^{-1}\right)$ e silte $\left(\mathrm{g} \mathrm{kg}^{-1}\right)$ divididos por 1.000 , menos a argila $\left(\mathrm{g} \mathrm{kg}^{-1}\right)$;

S1 = estrutura do solo, conforme codificação por Wischmeier, Johnson e Cross (1971);

$\mathrm{P}=$ permeabilidade do solo, conforme codificação por Wischmeier, Johnson e Cross (1971).

Com o objetivo de comparar os valores de erodibilidade do solo com outros estudos, os valores estimados pelos três métodos foram classificados, segundo Mannigel et al. (2002), em: extremamente alta, para $\mathrm{K}>0,060 \mathrm{Mg} \mathrm{h} \mathrm{MJ}^{-1} \mathrm{~mm}^{-1}$; muito alta, para K entre 0,045 e 0,060

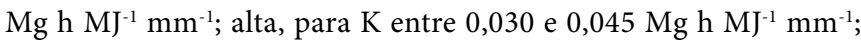
média, para K entre 0,015 e $0,030 \mathrm{Mg} \mathrm{h} \mathrm{MJ}^{-1} \mathrm{~mm}^{-1}$; baixa, para $\mathrm{K}$ entre 0,009 e $0,015 \mathrm{Mg} \mathrm{h} \mathrm{MJ}^{-1} \mathrm{~mm}^{-1}$; e muito baixa, para $\mathrm{K}$ menor que 0,009 $\mathrm{Mg} \mathrm{h} \mathrm{MJ}^{-1} \mathrm{~mm}^{-1}$.

O fator LS foi obtido segundo método proposto por Desmet e Govers (1996), em que o fator L se refere ao comprimento da encosta e o fator $\mathrm{S}$, ao grau de declividade. Esse fator é definido como a taxa de perda de solo por unidade de área de uma parcela-padrão de 22,13 m de comprimento e 9\% de declive (WISCHMEIER; SMITH, 1978). O fator L foi gerado a partir de conceitos da contribuição de cada pixel e direção do fluxo para gerar um produto que represente as condições encontradas no ambiente real (DESMET; GOVERS, 1996), apresentado pela Equação 5.

$L_{i, j}=\frac{\left[\left(A_{i, j-i n}+D^{2}\right)^{m 1+1}-\left(A_{i, j-i n}\right)^{m 1+1}\right.}{\left[D^{m 1+2} x_{i, j}{ }^{m 1}(22,13)^{m 1}\right]}$

Em que:

$i$ e $j=$ coordenadas da célula localizada no mapa da bacia;

$A$ = área de fluxo acumulado;

$D=$ resolução da grade de células;

$\mathrm{m}=$ expoente do comprimento das encostas;

$x=$ declividade média da vertente.

O fator S é o produto desenvolvido com base na inclinação e elaborado com base no MDE do SRTM, com resolução espacial de $30 \mathrm{~m}$ e aplicado à equação de Wischmeier e Smith (1978) (Equação 6):

$S=\left[\left(0,00654 \times s^{2}\right)+(0,0456 \times s)+(0,065)\right]$

Em que:

$\mathrm{S}=$ fator grau de declive (\%);

$\mathrm{s}=$ grau de declive (\%) obtido por altimetria do MDE.

Para obter o fator cobertura do solo (fator C), primeiramente, foi realizada a classificação do uso da terra na BHAF a partir de imagens LandSat 8/OLI, com resolução de $30 \mathrm{~m}$, nas quatros estações do RS (verão, outono, inverno e primavera), para representar o fator sazonalidade agrícola e seu efeito na cobertura do solo na área deste estudo.

A escolha das imagens foi baseada na disponibilidade de imagens e cobertura de nuvens. A classificação resultou nas seguintes classes: água, área urbana, agricultura, floresta, pastagem/campo e solo exposto. Depois, $\mathrm{o}$ fator $\mathrm{C}$ foi obtido com base em valores de referência por meio de pesquisa bibliográfica (Tabela 2) para cada classe de uso da terra na bacia hidrográfica. $\mathrm{O}$ fator $\mathrm{P}$ foi considerado igual a 1 para toda a área, estabelecendo que não há práticas de controle da erosão, de acordo com o procedimento também adotado por Ozcan et al. (2008). 
A estimativa de perda de solo foi calculada pelo modelo RUSLE para quatro períodos agroclimáticos (verão, outono, inverno e primavera), sendo utilizados os fatores $\mathrm{C}$ e R referentes a cada período - os demais fatores foram constantes. Por fim, foi calculada a perda de solo anual média para a BHAF.

Para classificar as perdas de solo, foram utilizadas as classes propostas por Batista et al. (2017): < $1 \mathrm{Mg} \mathrm{ha}^{-1}$ ano $^{-1}$; entre 1 e $5 \mathrm{Mg} \mathrm{ha}^{-1}$ ano $^{-1}$; de 5 a $10 \mathrm{Mg} \mathrm{ha}^{-1}$ ano $^{-1}$; de 10 a $25 \mathrm{Mg} \mathrm{ha}^{-1}$ ano $^{-1}$; de 25 a $50 \mathrm{Mg}$ ha $^{-1}$ ano $^{-1}$; de 50 a $100 \mathrm{Mg} \mathrm{ha}^{-1}$ ano $^{-1}$; e $>100 \mathrm{Mg} \mathrm{ha}^{-1}$ ano $^{-1}$. A tolerância às perdas de solo para cada classe de solo da BHAF foi obtida conforme metodologia de Lombardi Neto e Bertoni (1975), conforme a Equação 7.

$\mathrm{T}=\mathrm{h} \cdot \mathrm{r} \cdot \mathrm{Ds} \cdot 100^{-1}$

Em que:

$\mathrm{T}=$ tolerância às perdas de solo $\left(\mathrm{Mg}_{\mathrm{ga}} \mathrm{ano}^{-1}\right)$;

$\mathrm{h}=$ profundidade efetiva do perfil $(\mathrm{mm})$;

Ds = Densidade do solo $\left(\mathrm{Mg} \mathrm{m}^{-3}\right)$;

$\mathrm{r}=$ índice associado à relação textural (RT), em que $\mathrm{r}=1$ para RT $<1,5 ; \mathrm{r}=0,75$ para RT entre 1,5 e 2,$5 ; \mathrm{r}=0,5$ para $\mathrm{RT}>2,5 ; 100^{-1}$ (ano) = representa a relação que expressa o tempo necessário para o desgaste de $1.000 \mathrm{~mm}$ de solo e o fator de conversão entre as unidades.

A densidade do solo utilizada se baseou no valor padrão de 1,250 $\mathrm{g} \mathrm{cm}^{-3}$.

Tabela 2 - Classes de uso da terra da Bacia Hidrográfica do Arroio Fragata, fator $\mathrm{C}$ obtido da literatura e valor médio utilizado.

\begin{tabular}{|c|c|c|c|}
\hline $\begin{array}{l}\text { Classes de uso } \\
\text { da terra }\end{array}$ & Fator C & $\begin{array}{l}\text { Fator C } \\
\text { médio }\end{array}$ & Referências \\
\hline Água & 0,0000 & 0,0000 & Bertoni e Lombardi Neto (2014) \\
\hline \multirow{4}{*}{ Floresta } & 0,0010 & \multirow{4}{*}{0,0005} & Graça et al. (2015) \\
\hline & 0,0004 & & Silva et al. (2010) \\
\hline & 0,0004 & & Demarchi (2012) \\
\hline & 0,0001 & & Lino (2010) \\
\hline \multirow{8}{*}{$\begin{array}{l}\text { Pastagem/ } \\
\text { Campo }\end{array}$} & 0,0100 & \multirow{8}{*}{0,01466} & Silva et al. $(2010)^{\star}$ \\
\hline & 0,0050 & & Silva et al. $(2010)^{\star}$ \\
\hline & 0,0200 & & Macedo et al. (2O12) \\
\hline & 0,0070 & & Galdino $(2012)^{*}$ \\
\hline & 0,0143 & & Galdino $(2012)^{*}$ \\
\hline & 0,0010 & & Silva et al. (2010)* \\
\hline & 0,0500 & & Silva et al. (2010)* \\
\hline & 0,0100 & & Graça et al. (2015) \\
\hline Agricultura & 0,0648 & 0,0648 & Didoné et al. (2014) \\
\hline Solo exposto & 1,0000 & 1,0000 & Macedo et al. (2012) \\
\hline $\begin{array}{l}\text { Área urbana / } \\
\text { industrial }\end{array}$ & 0,0000 & 0,0000 & - \\
\hline
\end{tabular}

*A variação nos valores representa condições diferentes de níveis de conservação de campos nativos e pastagens.

\section{RESULTADOS E DISCUSSÃO}

As estimativas do fator $\mathrm{K}$, obtidas pelos três métodos, oscilaram entre

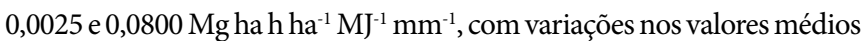
entre os métodos e classes de solo (Figura 3). As classes dos GMve e GMve + OX apresentaram os maiores valores de erodibilidade estimados pelos métodos 1 e 2 (equações propostas por Denardin, 1990), sendo o valor mais alto observado para o método 2 (equação desenvolvida para solos brasileiros) para ambas as classes de solos $(0,0818 \mathrm{Mg}$ ha $\mathrm{h}$ $\mathrm{ha}^{-1} \mathrm{MJ}^{-1} \mathrm{~mm}^{-1}$ ), sendo classificado como extremamente alto (Figura 3 ). Já para o método 3 (equação de Wischmeier, Johnson e Cross, 1971), os valores dessas mesmas classes de solo reduziram significativamente $\left(0,0220 \mathrm{Mg}\right.$ ha h ha-1 $\left.\mathrm{MJ}^{-1} \mathrm{~mm}^{-1}\right)$ (Figura 3). A erodibilidade observada para a classe GMve está relacionada ao tipo de estrutura (prismática, colunar e laminar) e ao alto teor de silte $(\sim 41 \%)$ presente nesse solo, além da presença de horizonte com maior gradiente de argila, que confere menor permeabilidade ao perfil de solo e menor taxa de infiltração de água (LEITE et al., 2009; SCOPEL; SOUSA; MARTINS, 2013).

Para os três métodos, os menores valores do fator K são observados para a classe ESKo $\left(0,0025 \mathrm{Mg}\right.$ ha h ha $\left.{ }^{-1} \mathrm{MJ}^{-1} \mathrm{~mm}^{-1}\right)$, demonstrando grande resistência aos processos erosivos. Tal resultado está associado à textura arenosa/francoarenosa dessa classe de solo, refletindo em uma permeabilidade moderadamente rápida, o que resulta em alta taxa de infiltração de água no perfil (SCOPEL; SOUSA; MARTINS, 2013). Bonilla e Johnson (2012) observaram, para 535 amostras, que a erodibilidade do solo diminui à medida que o teor de areia aumenta. Os autores atribuíram ao fato que à medida que o tamanho da partícula aumenta, além do intervalo de 20 a $200 \mu \mathrm{m}$, torna-se mais difícil o transporte das partículas em razão da maior densidade.

As demais classes de solo apresentaram valores semelhantes de erodibilidade entre os três métodos de estimativa (Figura 3), o que está relacionado à presença do horizonte $\mathrm{B}$ textural no perfil, exceto para a classe dos RRd. A classe dos argissolos e dos planossolos geralmente mostra altos valores de erodibilidade em razão da presença de gradiente textural e/ou mudanças texturais abruptas. Essas características favorecem a erosão pela baixa permeabilidade do horizonte subsuperficial, facilitando o escoamento superficial por exceder a capacidade de infiltração de água no solo, principalmente em chuvas de maior intensidade.

Os valores do fator $\mathrm{K}$ estimados pelo método 2 para os argissolos (Argissolo Bruno-Acinzentado - PBAC = 0,0351 e Argissolo Vermelho-Amarelo - PVA $=0,0301 \mathrm{Mg}$ ha h ha ${ }^{-1} \mathrm{MJ}^{-1} \mathrm{~mm}^{-1}$ ) foram classificados em alto (Figuras 3 e 4A), sendo semelhantes aos registrados por Carvalho et al. (2014) (0,0303 $\mathrm{Mg}$ ha h ha-1 $\left.\mathrm{MJ}^{-1} \mathrm{~mm}^{-1}\right) \mathrm{e}$

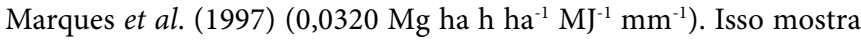
que a equação desenvolvida apenas com solos do Brasil (DENARDIN, 1990) - método 2 - é mais coerente em relação aos métodos 1 e 3.

A BHAF é caracterizada pela presença de aproximadamente $47 \%$ de sua extensão sobre relevo plano e suave ondulado (0 a 8\%) (Tabela 3). 
Essas áreas situam-se na parte sudeste da bacia, onde o fator LS apresentou os menores valores (Figura 4B). As áreas com declividade entre $8 \mathrm{e}$ $45 \%$ estão localizadas com maior representatividade na parte noroeste da bacia, representado $53 \%$ da área (Tabela 3), onde o fator LS apresentou os maiores valores (Figura 4B). A representatividade de relevo ondulado na área é de 48,07\% (Tabela 3). Nessas áreas, predomina a classe dos argissolos com grau de erodibilidade classificado como alta (Figura 3). Silva et al. (2010) alertam que isso pode ser suficiente para desencadear processos erosivos acelerados localizados, mas com grande magnitude na taxa de perda de solo, caso não haja a devida conservação do solo. Em Moura-Bueno et al. (2018), foram registradas maiores perdas de solo para a classe dos PBAC em uma bacia hidrográfica na Região Sul do Brasil. Os autores relacionaram tal resultado com as características pedológicas, o relevo ondulado e o uso da terra. Durães e Mello (2016) destacam que as maiores perdas de solo estão associadas com locais da paisagem de maior fator LS.

A avaliação da sazonalidade da cobertura do solo em diferentes épocas do ano possibilitou o entendimento da dinâmica do fator $\mathrm{C}$ na BHAF, sendo possível definir as áreas e épocas em que são mais suscetíveis ao processo erosivo. Os mapas do fator cobertura do solo e práticas conservacionistas $(\mathrm{CP})$ mostram que na BHAF predominam áreas com solo coberto (Figura 5) em razão do predomínio da atividade pecuária na região. Fica evidente também a relação entre o solo exposto (maiores valores de $\mathrm{CP}$ ) e as atividades agrícolas nos quatro períodos do ano, com destaque para a região sul da bacia (Figuras 5A, 5B, 5D e 5E). Nessas áreas, há um aumento nas áreas de solo exposto, sendo essa maior nos períodos do verão e da primavera (Figuras $5 \mathrm{~A}$ e $5 \mathrm{E}$, respectivamente) em razão do tempo em que o solo fica descoberto no intervalo entre a colheita das culturas anuais e a semeadura das culturas subsequentes.

A avaliação sazonal do fator CP permitiu identificar os períodos e os locais com altos índices de solo exposto, como no verão (Figura 5A), onde as chuvas erosivas têm maior ocorrência (Tabela 1), conferindo maior potencial erosivo em razão do impacto da gota de chuva em solo descoberto, corroborando com Oliveira, Wendland e Nearing (2012). Isso evidencia a necessidade de cobertura do solo, principalmente nesses períodos, para que ocorra a dissipação da energia do impacto das gotas e ocorra maior infiltração de água, reduzindo o escoamento superficial (LEITE et al., 2009; EVRARD et al., 2010).

Variações na erosividade das chuvas também foram observadas por Batista et al. (2017) em uma bacia hidrográfica no estado de Minas Gerais. Segundo os autores, tal variação é resultado da variabilidade do relevo. Similar comportamento foi observado por Buriol et al. (2013) na bacia do rio Vacacaí, no RS, em que variações mensais no volume de

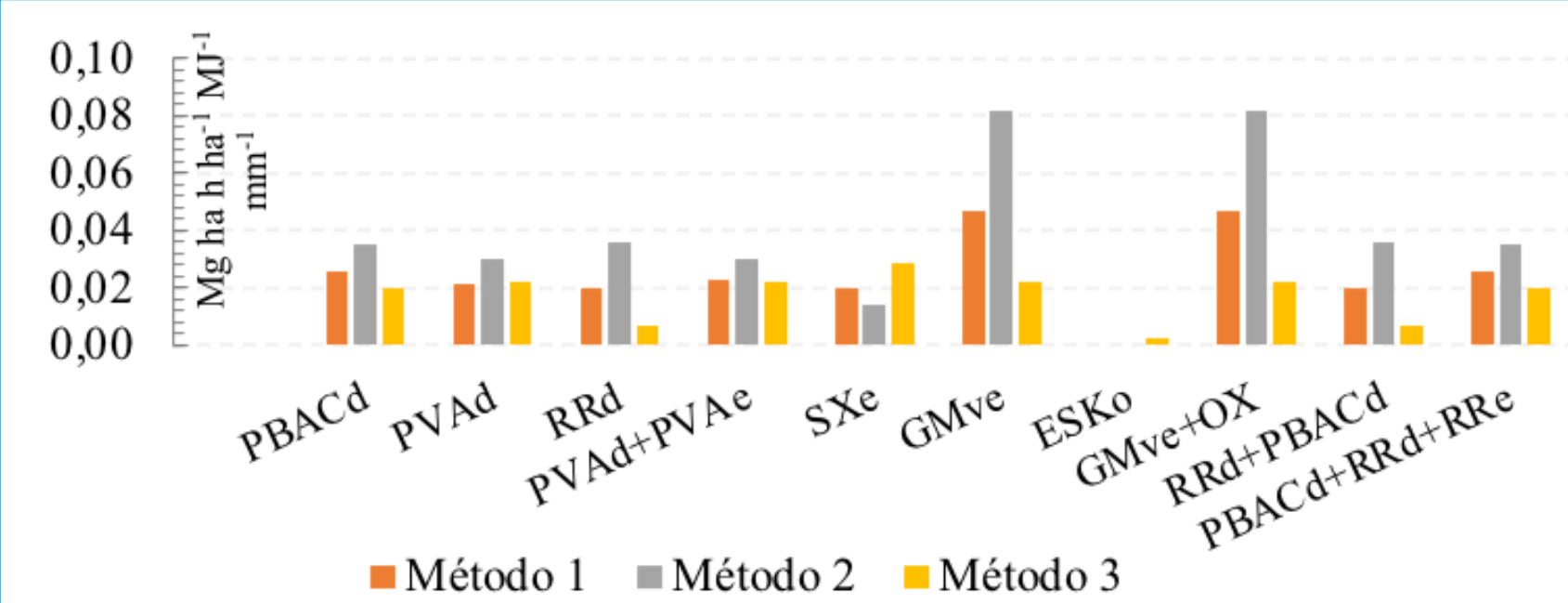

PBACd: Argissolo Bruno-Acinzentado Distrófico; PVAd: Argissolo Vermelho-Amarelo Distrófico; RRd: Neossolo Regolítico Distrófico; PVAd + PVAe: Argissolo VermelhoAmarelo Distrófico + Argissolo Vermelho-Amarelo Eutrófico; SXe: Planossolo Háplico Eutrófico; GMve: Gleissolo Melânico Ta Eutrófico; ESKo: Espodossolo FerriHumilúvico Órtico; GMve + OX: Gleissolo Melânico Ta Eutrófico + Organossolo Háplico; RRd + PBACd: Neossolo Regolítico Distrófico + Argissolo Bruno-Acinzentado Distrófico; PBACd + RRd + RRe: Argissolo Bruno-Acinzentado Distrófico + Neossolo Regolítico Distrófico + Neossolo Regolítico Eutrófico.

Figura 3 - Valores médios de erodibilidade estimados por meio dos métodos 1 e 2 de Denardin (1990) e do método 3 de Wischmeier, Johnson e Cross (1971) para os solos da Bacia Hidrográfica do Arroio Fragata.

Tabela 3 - Classes de declividade da Bacia Hidrográfica do Arroio Fragata.

\begin{tabular}{|c|c|c|c|c|c|c|c|}
\hline \multicolumn{2}{|c|}{ Classe de declividade (\%) } & $\begin{array}{l}\text { Plano } \\
(0-3)\end{array}$ & $\begin{array}{l}\text { Suave ondulado } \\
\qquad(3-8)\end{array}$ & $\begin{array}{l}\text { Ondulado } \\
(8-20)\end{array}$ & $\begin{array}{l}\text { Forte ondulado } \\
(20-45)\end{array}$ & $\begin{array}{c}\text { Montanhoso } \\
(45-75)\end{array}$ & Total \\
\hline \multirow{2}{*}{ Área } & Absoluta $\left(\mathrm{km}^{2}\right)$ & 69,11 & 36,75 & 108,33 & 11,10 & 0,05 & 225,34 \\
\hline & Relativa (\%) & 30,67 & 16,31 & 48,07 & 4,92 & 0,02 & 100,00 \\
\hline
\end{tabular}


precipitação e potencial erosivo, mesmo em pequenas distâncias, foram associadas ao microclima regido pelo relevo. Essas variações afetam diretamente a variabilidade das perdas de solo na paisagem (BOIX-FAYOS et al., 2006), indicando a necessidade do monitoramento local e regional desse fator para fins de modelagem das perdas de solo por erosão hídrica.

A integração de todos os fatores da RUSLE resultou no mapa de perdas de solo para os quatro períodos e média anual (Figura 6). Quanto às perdas médias anuais de solo, a BHAF apresentou média anual de 12,56 $\mathrm{Mg} \mathrm{ha}^{-1}$ ano $^{-1}$ (Figura 6C) e os valores variaram entre 0 e 3995,11 Mg ha $^{-1}$ ano $^{-1}$. Na maior parte da bacia (63,53\%), a estimativa de perda de solo anual é de 0 a $5 \mathrm{Mg} \mathrm{ha}^{-1}$ ano $^{-1}$ (Tabela 4 e Figura 6C). Segundo a classificação de Batista et al. (2017), esses valores caracterizam-se por não apresentarem riscos à conservação dos solos. Essa situação ocorre por causa do baixo valor do fator $\mathrm{CP}(<0,5)$ para a maior parte da bacia hidrográfica (Figura 5C).

Observa-se que $21,65 \%$ da bacia apresenta perdas de solo maiores que $10 \mathrm{Mg} \mathrm{ha}^{-1}$ ano $^{-1}$ (Tabela 4), sendo estas muito próximas e/ou acima da tolerância para a maioria das classes de solos que ocorrem na BHAF (Tabela 5). Tal resultado está associado com locais da bacia com valores altos de LS (> 1,5 - Figura 4B) e CP (>0,5 - Figura 5C). Já perdas de solo maiores que $25 \mathrm{Mg} \mathrm{ha}^{-1}$ ano $^{-1}$ ocorrem em apenas $11,89 \%$ de sua área (Tabela 4). Essas áreas estão associadas ao alto valor do fator $\mathrm{CP}$ $(>0,7)$ (Figura 5C) e aos solos com alta erodibilidade na região sul da bacia (Figura 4B). Portanto, deve-se considerar que as perdas médias entre 5 e $25 \mathrm{Mg} \mathrm{ha}^{-1}$ ano $^{-1}$ devem ser controladas para ocorrer processos erosivos mais intensos (BATISTA et al., 2017). O avanço do processo erosivo acelerado relacionado à expansão de lavouras e à redução da cobertura do solo é discutido em Couto Júnior et al. (2019), em que os autores alertam para o aumento das perdas de solos em uma bacia hidrográfica no estado de São Paulo. Da mesma forma, Didoné et al. (2014) mostram que a falta de práticas conservacionistas em áreas de lavoura no RS é a principal causa do processo erosivo acelerado e, consequentemente, da produção de sedimentos.

Áreas com perdas médias estão relacionadas à mudança no uso da terra, pois se distribuem por toda a bacia hidrográfica sem se restringirem a condições de relevo ou clima. A primavera apresentou, em média, a maior perda de solo $\left(4,6 \mathrm{Mg} \mathrm{ha}^{-1}\right.$ ano $\left.^{-1}\right)$ (Figura 6E). As perdas de solo são mais expressivas no verão e na primavera e em função do

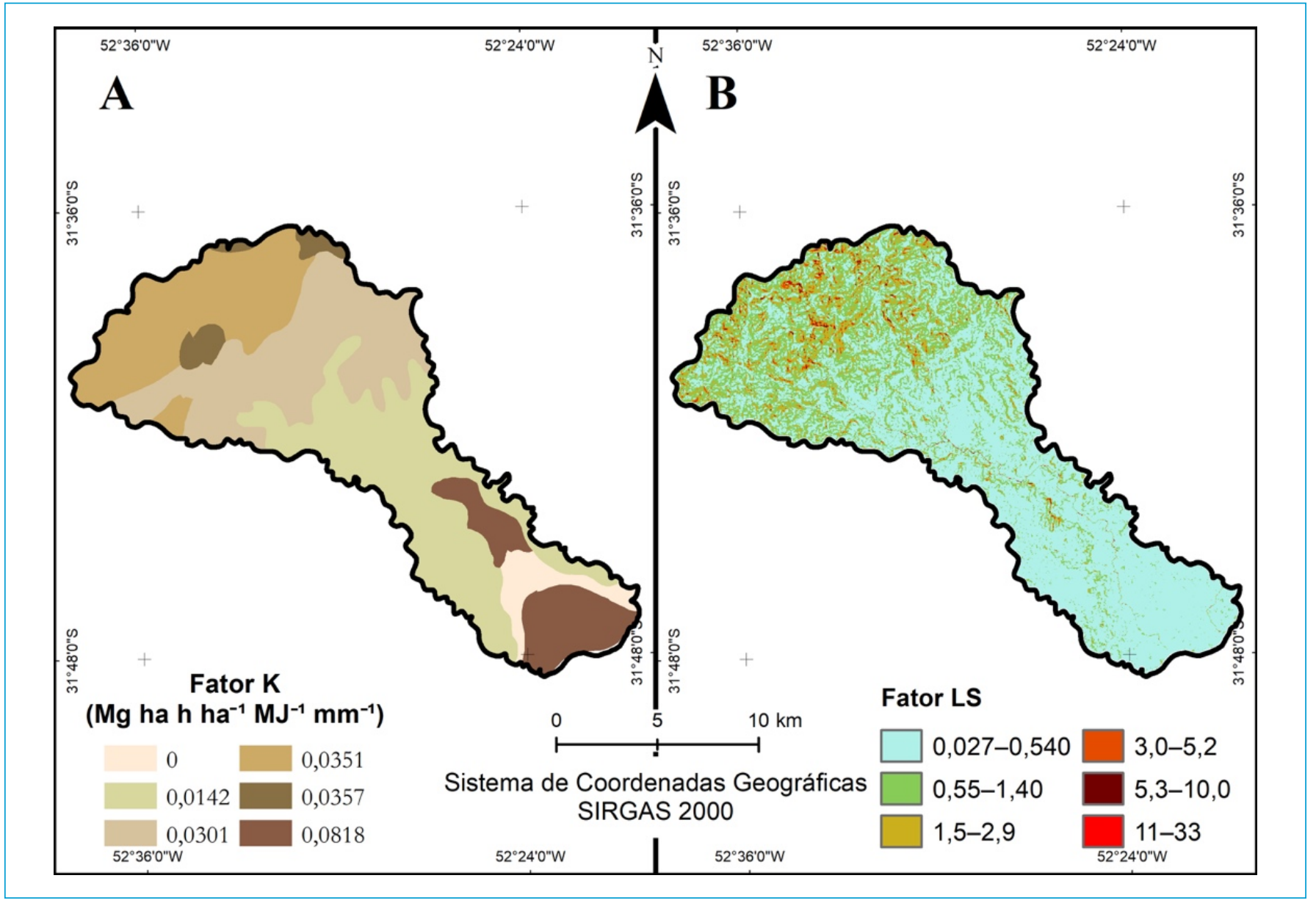

Figura 4 - (A) Mapa do fator de erodibilidade (K) estimado pelo método 2 e (B) mapa do fator de comprimento e grau do declive (LS) para a Bacia Hidrográfica do Arroio Fragata. 
fato de que nessa época existem maiores áreas de solo exposto, fator $\mathrm{CP}$ $>0,5$ (Figuras 5A e 5E), em razão do preparo para cultivos agrícolas.

Destaca-se que os períodos com perdas entre 5 e $25 \mathrm{Mg} \mathrm{ha}^{-1} \mathrm{ano}^{-1}$ ocorrem no verão $(9,11 \%)$ e na primavera $(8,40 \%)$. No verão, os índices

Tabela 4 - Classificação das perdas de solo médias anuais conforme metodologia de Batista et al. (2017) para a Bacia Hidrográfica do Arroio Fragata.

\begin{tabular}{|c|c|c|}
\hline \multirow{2}{*}{$\begin{array}{l}\text { Perdas de solo } \\
\left(\text { Mg ha }^{-1} a^{-1}\right)\end{array}$} & \multicolumn{2}{|c|}{ Área } \\
\hline & Absoluta $\left(\mathrm{km}^{2}\right)$ & Relativa (\%) \\
\hline$<1$ & 90,55 & 40,19 \\
\hline 1a 5 & 53,50 & 23,75 \\
\hline 5 a 10 & 19,83 & 8,80 \\
\hline 10 a 25 & 21,99 & 9,76 \\
\hline 25 a 50 & 8,86 & 3,93 \\
\hline 50 a 100 & 12,08 & 5,36 \\
\hline$>100$ & 5,85 & 2,60 \\
\hline Água & 2,73 & 1,21 \\
\hline Area industrial & 0,41 & 0,18 \\
\hline Área urbana & 9,49 & 4,21 \\
\hline Total & 225,29 & 100 \\
\hline
\end{tabular}

Tabela 5 - Valores de perda de solo e tolerância às perdas de solo calculadas com base no método de Lombardi Neto e Bertoni (1975) para as classes de solos da Bacia Hidrográfica do Arroio Fragata.

\begin{tabular}{|c|c|c|}
\hline Classes de solos & $\begin{array}{l}\text { Perdas médias de solo } \\
\left(\mathrm{Mg} \mathrm{ha}^{-1} \mathrm{ano}^{-1}\right)\end{array}$ & $\begin{array}{c}\text { Tolerância às perdas } \\
\text { de solo } \\
\left(\mathrm{Mg} \mathrm{ha}^{-1} \text { ano }^{-1}\right)\end{array}$ \\
\hline ESKo & 5,19 & 8,50 \\
\hline GMve & 6,13 & 5,73 \\
\hline GMve + OX & 5,99 & 5,73 \\
\hline PBACd & 10,03 & 3,34 \\
\hline$P B A C d+R R d+R R e$ & 17,12 & 3,31 \\
\hline PVAd & 18,40 & 2,90 \\
\hline PVAd + PVAe & 13,05 & 3,43 \\
\hline $\mathrm{RRd}$ & 20,10 & 4,71 \\
\hline $\mathrm{RRd}+\mathrm{PBACd}$ & 19,17 & 3,31 \\
\hline sXe & 6,84 & 3,00 \\
\hline
\end{tabular}

ESKo: Espodossolo Ferri-Humilúvico Órtico; GMve: Gleissolo Melânico Ta Eutrófico; GMve + OX: Gleissolo Melânico Ta Eutrófico+Organossolo Háplico; PBACd: Argissolo Bruno-Acinzentado Distrófico; PBACd + RRd + RRe: Argissolo Bruno-Acinzentado Distrófico + Neossolo Regolítico Distrófico + Neossolo Regolítico Eutrófico; PVAd: Argissolo Vermelho-Amarelo Distrófico; PVAd + PVAe: Argissolo Vermelho-Amarelo Distrófico + Argissolo Vermelho-Amarelo Eutrófico; RRd: Neossolo Regolítico Distrófico; RRd + PBACd: Neossolo Regolítico Distrófico + Argissolo BrunoAcinzentado Distrófico; SXe: Planossolo Háplico Eutrófico.

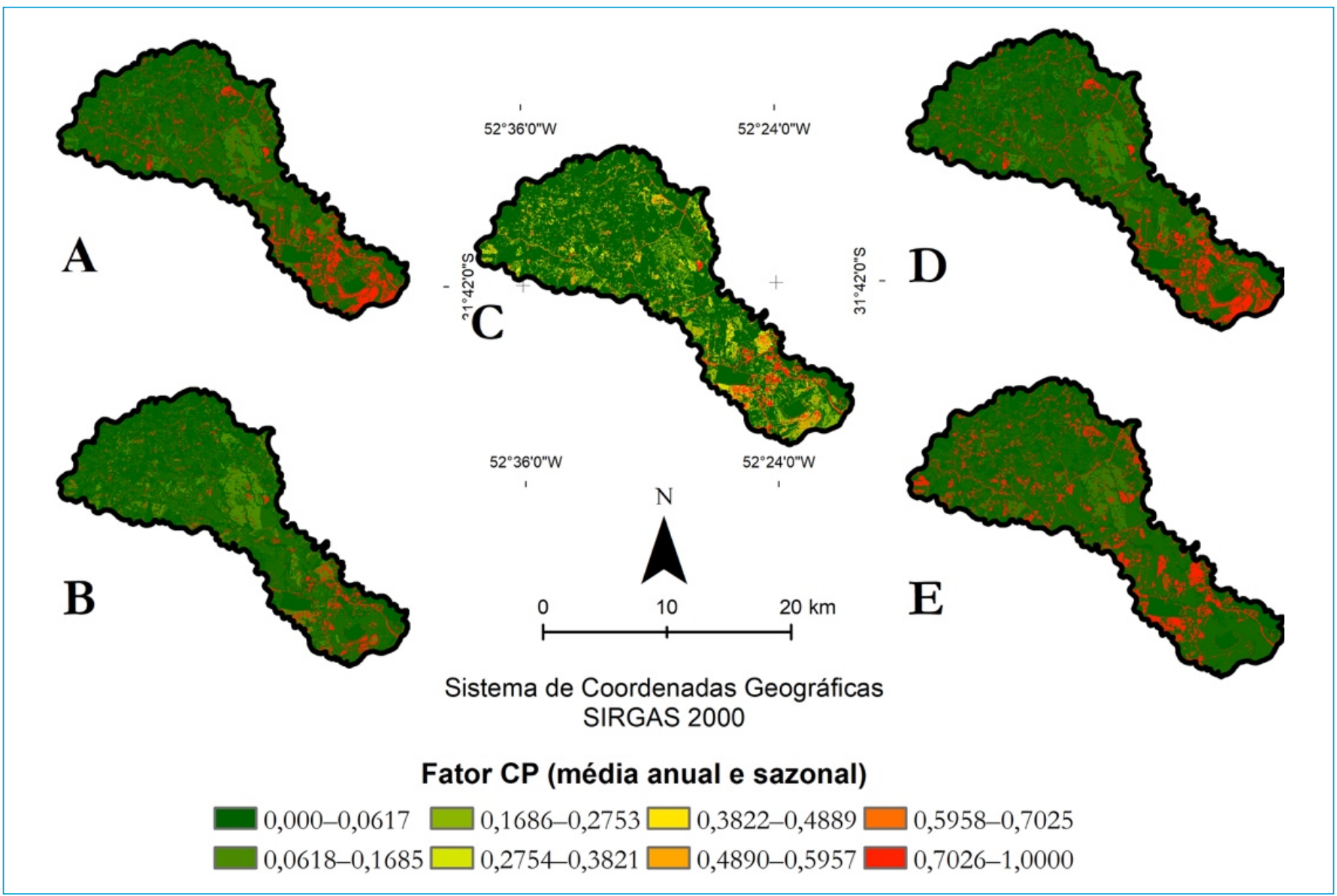

Figura 5 - Fator cobertura do solo e práticas conservacionistas para os períodos de (A) verão, (B) outono, (C) média anual, (D) inverno e (E) primavera da Bacia Hidrográfica do Arroio Fragata. 
de erosividade são mais expressivos na BHAF, enquanto na primavera, mesmo a erosividade sendo menor que nos demais períodos (Tabela 1), as áreas de solo exposto são maiores, refletindo no processo acelerado de desagregação das partículas causado pelo impacto da gota de chuva sobre o solo descoberto. Associado a isso, ocorre o fenômeno de salpicamento das partículas dispersas, causando a obstrução dos poros e a formação do selamento superficial, reduzindo a taxa de infiltração de água (LEITE et al., 2009), o que promove o aumento da enxurrada e resulta em maiores perdas de solo e água. No inverno e no outono, existe maior cobertura da terra, a qual propicia as menores taxas de perdas de solo na maior parte da $\operatorname{BHAF}\left(<1 \mathrm{Mg} \mathrm{ha}^{-1} \mathrm{ano}^{-1}\right.$ ) (Figuras $6 \mathrm{~B}$ e 6D). Esses resultados vão de encontro aos observados por Prado e Nóbrega (2005) em uma bacia hidrográfica no estado do Paraná, onde o período mais crítico para ocorrência do processo erosivo foi registrado na primavera, em razão da ocorrência de chuvas com maior potencial erosivo.

A modelagem das perdas de solo, levando em consideração a sazonalidade climática (fator R) e agrícola (fator $\mathrm{CP}$ ), mostrou ser eficiente no estudo da dinâmica do processo erosivo na BHAF, sendo possível identificar os fatores que determinam a magnitude das perdas de solo, além dos locais e períodos do ano em que ocorrem as maiores taxas de erosão hídrica. Essa abordagem pode ser adotada para outras áreas da Região Sul do Brasil, visando tornar o diagnóstico do processo erosivo mais preciso e detalhado. Estudos nessa linha em outros locais do mundo mostram que as maiores taxas de erosão estão relacionadas a ecossistemas frágeis que sofreram mudanças no uso terra e confirmam que os fatores que mais influenciam a erosão do solo são os fatores K, LS e CP (ZHOU et al., 2008; WANG et al., 2016).

As perdas de solo e a tolerância às perdas para as classes de solo da BHAF são apresentadas na Tabela 5. Nota-se que as classes dos argissolos e dos neossolos apresentaram as maiores perdas de solo e maiores níveis de erosão hídrica acima do limite tolerável (Tabela 5). Os PVAd apresentaram $51 \%$ de sua área com valores acima do limite tolerável (2,90 $\mathrm{Mg} \mathrm{ha}^{-1}$ ano $^{-1}$ - Tabela 5). Já os RRd exibiram somente $24 \%$ de sua área com valores superiores a 4,71 Mg ha-1 ano $^{-1}$ (Tabela 5),

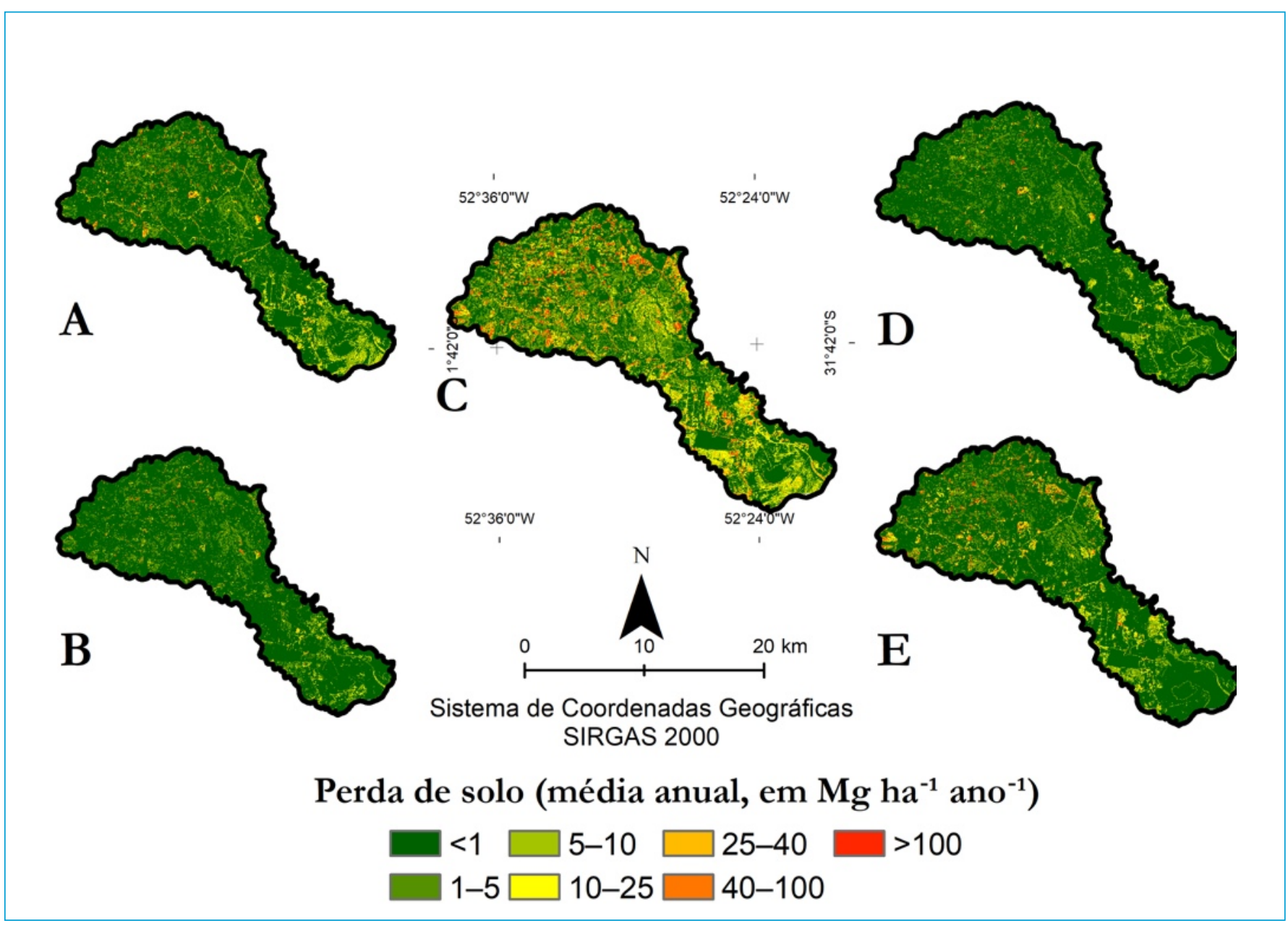

Figura 6 - Perdas de solo nos períodos de (A) verão, (B) outono, (C) média anual, (D) inverno e (E) primavera da Bacia Hidrográfica do Arroio Fragata. 
o que é causado pelo efeito positivo da cobertura do solo nessas áreas de neossolos.

A classe dos PVA representa aproximadamente $24 \%$ da BHAF, apresenta alta erodibilidade (Figura 3) e ocorre na paisagem em locais com fator LS alto (Figura 4B). Esses fatores propiciam maior suscetibilidade à erosão para a região sul da BHAF. Os planossolos representam $31 \%$ da área e apresentam alta suscetibilidade ao processo erosivo em razão da baixa infiltração de água no solo, causada pela presença de horizonte B textural. No entanto, ocorrem em locais onde o fator LS é baixo (Figura 4B), resultando em perdas moderadas, como se observa na parte sul da BHAF (Figura 6C).

A espacialização da relação entre a tolerância à perda e a perda média anual de solo para a BHAF é apresentada na Figura 7. Nota-se que existe uma distribuição homogênea ao longo de sua extensão, em que $36 \%$ da área da bacia se encontra com perdas acima dos limites toleráveis, enquanto $64 \%$ se situam abaixo dos limiares de tolerância. Não há um fator específico controlando o processo erosivo na área, e sim as combinações dos cinco fatores da RUSLE. Alguns desses fatores apresentam maior contribuição para que ocorra aumento nas perdas de solo em locais específicos da bacia hidrográfica. Na cabeceira da bacia, o fator LS apresentou maior efeito sobre as perdas de solo. Na parte sul, os fatores $\mathrm{K}$ e CP mostraram ter maior influência no processo erosivo.

Os resultados encontrados neste estudo indicam que a abordagem da integração entre a dinâmica espacial e temporal de fatores relacionados ao processo erosivo em uma bacia hidrográfica é uma estratégia útil para quantificar as perdas de solo em bacias hidrográficas brasileiras, com destaque para a Região Sul, onde existem variações mensais no volume de precipitação e potencial erosivo, mesmo em pequenas distâncias, associadas ao microclima regido pelo relevo (Buriol et al., 2013). É importante ressaltar que os resultados encontrados neste estudo são uma estimativa inicial da dinâmica de erosão hídrica na BHAF. Dados de campo de perdas de solo devem ser coletados com o objetivo de validar as estimativas do modelo RUSLE.

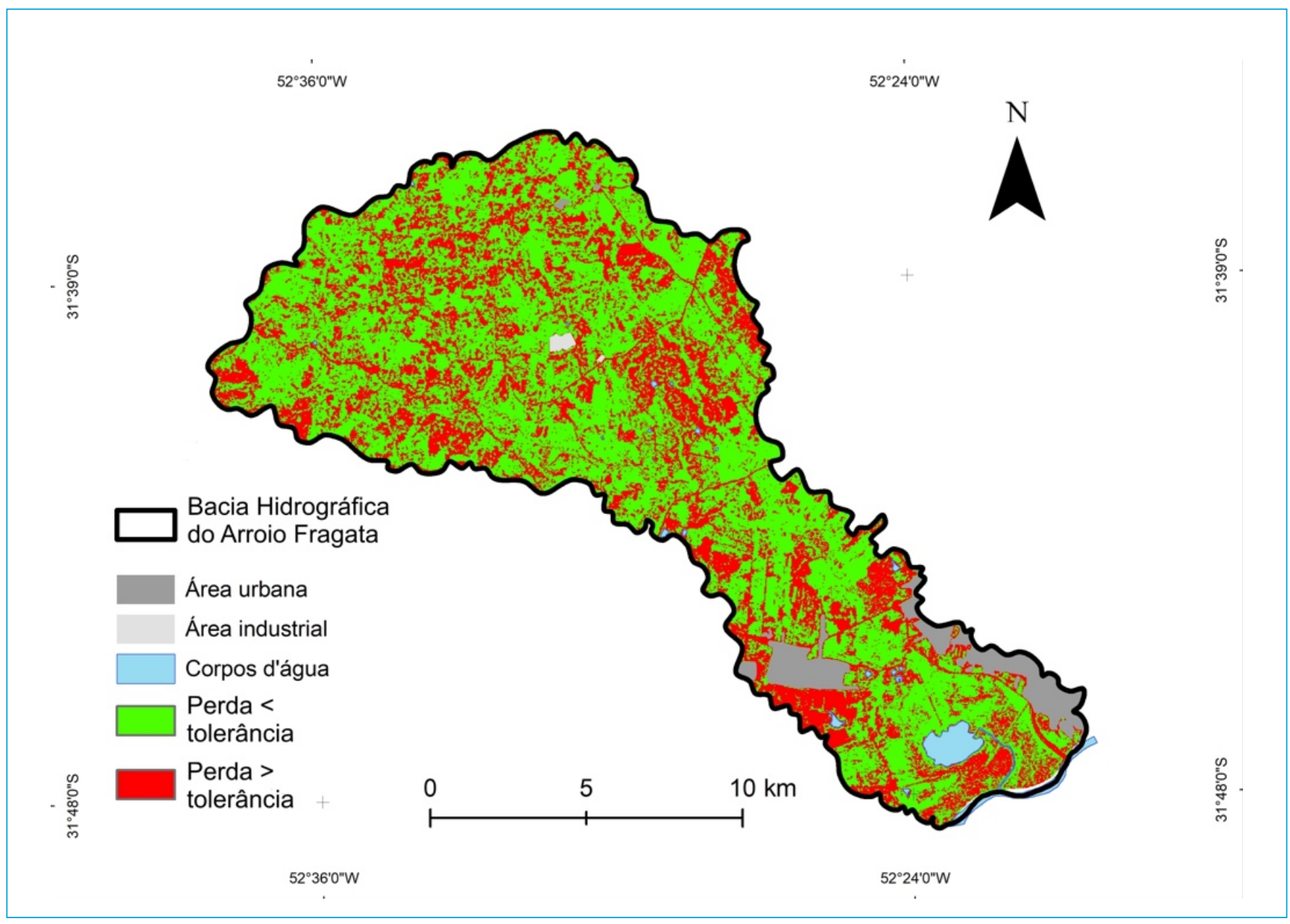

Figura 7 - Relação entre as perdas de solo e a tolerância às perdas de solo na Bacia Hidrográfica do Arroio Fragata. 


\section{CONCLUSÕES}

A integração entre a dinâmica espacial e temporal de fatores do modelo RUSLE relacionados ao processo erosivo se mostrou uma estratégia eficiente para avaliar o efeito da variação sazonal agroclimática nas perdas de solo da BHAF.

A variação sazonal agroclimática teve efeito na perda de solo, com as maiores taxas de erosão no período de verão e de primavera.
Perdas de solo entre 5 e $50 \mathrm{Mg} \mathrm{ha}^{-1}$ ano $^{-1}$ foram registradas em $24 \%$ da BHAF, sendo associadas a períodos de chuvas mais erosivas, maior declividade e baixa cobertura do solo.

Os fatores da RUSLE com maior contribuição no processo erosivo foram R, LS e CP, com efeitos distintos em locais específicos da BHAF.

\section{REFERÊNCIAS}

ALVARES, C.A.; STAPE, J.L.; SENTELHAS, P.C.; MORAES GONÇALVES, J.L.; SPAROVEK, G. (2013) Köppen's climate classification map for Brazil. Meteorologische Zeitschrift, v. 22, n. 6, p. 711-728. https://doi. org/10.1127/0941-2948/2013/0507

ANACHE, J.A.A.; WENDLAND, E.C.; OLIVEIRA, P.T.S.; FLANAGAN, D.C.; NEARING, M.A. (2017) Runoff and soil erosion plot-scale studies under natural rainfall: A meta-analysis of the Brazilian experience. Catena, v. 152, p. 29-39. https://doi.org/10.1016/j. catena.2017.01.003

BARROS, E.N.S.; VIOLA, M.R.; RODRIGUES, J.A.M.; MELLO, C.R.; AVANZI, J.C.; ALVES, M.V.G. (2O18) Modelagem da erosão hídrica nas bacias hidrográficas dos rios Lontra e Manoel Alves Pequeno, Tocantins. Revista Brasileira de Ciências Agrárias, v. 13, n. 1, p. 1-9. https://doi.org/10.5039/agraria.v13i1a5509

BATISTA, P.V.G.; SILVA, M.L.N.; SILVA, B.P.C.; CURI, N.; BUENO, I.T.; ACÉRBI JÚNIOR, F.W.; DAVIES, J.; QUINTON, J. (2O17) Modelling spatially distributed soil losses and sediment yield in the upper Grande River Basin - Brazil. Catena, v. 157, p. 139-150. https://doi. org/10.1016/j.catena.2017.05.025

BERTONI, J.; LOMBARDI NETO, F. (2014) Conservação do Solo. 9a ed. São Paulo: Ícone. 360 p.

BESKOW, S.; MELLO, C.R.; NORTON, L.D.; CURI, N.; VIOLA, M.R.; AVANZI, J.C. (2009) Soil erosion prediction in the Grande River Basin, Brazil using distributed modeling. Catena, v. 79, n. 1, p. 49-59. https://doi.org/10.1016/j.catena.2009.05.010

BOIX-FAYOS, C.; MARTÍNEZ-MENA, M.; ARNAU-ROSALÉN, E.; CALVO-CASES, A.; CASTILLO, V.; ALBALADEJO, J. (2006) Measuring soil erosion by field plots: Understanding the sources of variation. Earth-Science Reviews, v. 78, n. 3-4, p. 267-285. https:// doi.org/10.1016/j.earscirev.2006.05.005

BONILLA, C.A.; JOHNSON, O.I. (2012) Soil erodibility mapping and its correlation with soil properties in Central Chile. Geoderma, v. 189-190, p. 116-123. https://doi.org/10.1016/j.geoderma.2012.05.005

BURIOL, G.A.; STEFANEL, V.; SWAROWSKY, A.; CADEMARTORI, R.T.O. (2013) Homogeneidade espacial da precipitação pluvial na bacia hidrográfica do Rio Vacacaí, RS. Ciência Rural, v. 43, n. 12, p. 2160-2167. http://doi.org/10.1590/S0103-84782013005000131
CÂMARA, G.; SOUZA, R.C.M.; FREITAS, U.M.; GARRIDO, J. (1996) Spring: Integrating remote sensing and gis by object-oriented data modelling. Computers \& Graphics, v. 20, n. 3, p. 395-403. https://doi. org/10.1016/0097-8493(96)00008-8

CARVALHO, D.F.; DURIGON, V.L.; ANTUNES, M.A.H.; ALMEIDA, W.S. OLIVEIRA, P.T.S. (2014) Predicting soil erosion using Rusle and NDVI time series from TM Landsat 5. Pesquisa Agropecuária Brasileira, v. 49, n. 3, p. 215-224. http://doi.org/10.1590/S0100-204X2014000300008

CERA, J.C.; FERRAZ, S.E.T. (2015) Variações climáticas na precipitação no sul do Brasil no clima presentee futuro. Revista Brasileira de Meteorologia, v. 30, n. 1, p. 81-88. http://doi.org/10.1590/0102-778620130588

COUTO JÚNIOR, A.A.; CONCEIÇÃO, F.T.; FERNANDES, A.M.; SPATTI JUNIOR, E.P.; LUPINACCI, C.M.; MORUZZI, R.B. (2019) Land use changes associated with the expansion of sugar cane crops and their influences on soil removal in a tropical watershed in São Paulo State (Brazil). Catena, v. 172, p. 313-323.

CUNHA, N.G.; SILVEIRA, R.J.C. (1996a) Estudo dos solos do município de Capão do Leão. EMBRAPA-CPACT (Documentos, 11/96). Pelotas: Ed. UFPel. 54 p.

CUNHA, N.G.; SILVEIRA, R.J.C. (1996b) Estudo dos solos do município de Pelotas. EMBRAPACPACT (Documentos, 12/96) Pelotas: Ed. UFPel. 50 p.

CUNHA, N.G.; SILVEIRA, R.J.C.; SEVERO, C.R.S. (1996) Estudo dos solos do município de Morro Redondo. EMBRAPA-CPACT (Documentos, 23/96). Pelotas: Ed. UFPel. 28 p.

DEMARCHI, J.C. (2012) Geotecnologias aplicadas à estimativa de perda de solo por erosão hídrica na sub-bacia do Ribeirão das Perobas, municipio de Santa Cruz do Rio Pardo-SP. 150f. Dissertação (Mestre em Agronomia - Energia na agricultura) Universidade Estadual Paulista “Júlio de Mesquita Filho”, Botucatu.

DENARDIN, J.E. (1990) Erodibilidade do solo estimada por meio de parâmetros físicos e químicos. 114f. Tese (Doutorado) - Escola Superior de Agricultura Luiz de Queiroz, Piracicaba.

DESMET, P.; GOVERS, G. (1996) A GIS procedure for automatically calculating the USLE LS factor on topographically complex landscape units. Journal of Soil and Water Conservation, v. 51, n. 5, p. 427-433. 
DI STEFANO, C.; FERRO, V. (2O16) Establishing soil loss tolerance: an overview. Journal of Agricultural Engineering, v. 47, n. 3, p. 127-133. https://doi.org/10.4081/jae.2016.560

DIDONÉ, E.J.; MINELLA, J.P.G.; REICHERT, J.M.; MERTEN, G.H.; DALBIANCO, L.; BARRROS, C.A.P.; RAMON, R. (2014) Impact of no-tillage agricultural systems on sediment yield in two large catchments in Southern Brazil. Journal of Soils and Sediments, v. 14, p. 1287-1297. https://doi.org/10.1007/s11368-013-0844-6

DOTTERWEICH, M. (2013) The history of human-induced soil erosion: Geomorphic legacies, early descriptions and research, and the development of soil conservation-A global synopsis. Geomorphology, v. 201, p. 1-34. https://doi.org/10.1016/j. geomorph.2013.07.021

DURÃES, M.F.; MELLO, C.R. (2016) Distribuição espacial da erosão potencial e atual do solo na Bacia Hidrográfica do Rio Sapucaí, MG. Engenharia Sanitária e Ambiental, v. 21, n. 4, p. 677-685. https://doi. org/10.1590/s1413-41522016121182

EVRARD, O.; NORD, G.; CERDAN, O.; SOUCHËE, V.; LE BISSONNAIS, Y.; BONTÉ, P. (2010) Modelling the impact of land use change and rainfall seasonality on sediment export from an agricultural catchment of the northwestern European loess belt. Agriculture, Ecosystems and Environment, v. 138, n. 1-2, p. 83-94. https://doi. org/10.1016/j.agee.2010.04.003

FARR, T.G.; ROSEN, P.A.; CARO, E.; CRIPPEN, R.; DUREN, R.; HENSLEY, S.; KOBRICK, M.; PALLER, M.; RODRIGUEZ, E.; ROTH, L.; SEAL, D.; SHAFFER, S.; SHIMADA, J.; UMLAND, J.; WERNER, M.; OSKIN, M.; BURBANK, D.; ALSDORF, D. (2007) The Shuttle Radar Topography Mission. Reviews of Geophysics, v. 45, n. 2. https://doi. org/10.1029/2005RG000183

FERREIRA, V.; PANAGOPOULOS, T. (2014) Seasonality of Soil Erosion Under Mediterranean Conditions at the Alqueva Dam Watershed. Environmental Management, v. 54, n. 1, p. 67-83. https:// doi.org/10.1007/s00267-014-0281-3

GALDINO, S. (2012) Estimativa da perda de terra sob pastagens cultivadas em solos arenosos da bacia hidrográfica do Alto Taquari - MS/ST. Tese (Doutorado) - Universidade Estadual de Campinas, Campinas.

GAUBI, I.; CHAABANI, A.; BEN MAMMOU, A.; HAMZA, M.H. (2O17) A GIS-based soil erosion prediction using the Revised Universal Soil Loss Equation (RUSLE) (Lebna watershed, Cap Bon, Tunisia). Natural Hazards, v. 86, n. 1, p. 219-239. https://doi.org/10.1007/s11069-016-2684-3

GRAÇA, C.H.; PASSIG, F.H.; KELNIAR, A.R.; PIZA, M.A.; CARVALHO, K.Q.; ARANTES, E.J. (2O15) Muiltitemporal analysis of estimated soil loss for the river Mourão watershed, Paraná-Brazil. Brazilian Journal of Biology, v. 75, n. 4, supl. 2, p. 120-130. https://doi.org/10.1590/15196984.00613suppl

LAL, R.; SMITH, P.; JUNGKUNST, H.; MITSCH, W.; LEHMANN, J.; NAIR, R.; MCBRATNEY, A.; SÁ, J.; SCHNEIDER, J.; ZINN, Y.; SKORUPA, A.; ZHANG, H.; MINASNY, B.; SRINIVASRAO, C.; RAVINDRANATH, $H$. (2018) The carbon sequestration potential of terrestrial ecosystems. J. Soil and Water Conservation, v. 73, n. 6, p. 145-152. https://doi.org/10.2489/jswc.73.6.145A
LEITE, M.H.S.; COUTO, E.G.; AMORIM,S.S.A.; COSTA, E.L.; MARASCHIN, L. (2009) Perdas de solo e nutrientes num Latossolo VermelhoAmarelo Ácrico Típico, com diferentes sistemas de preparo e sob chuva natural. Revista Brasileira de Ciência do Solo, v. 33, n. 3, p. 689-699. https://doi.org/10.1590/S0100-06832009000300021

LINO, J.S. (2010) Evolução do sistema plantio direto e produção de sedimentos no Rio Grande do Sul. Dissertação (Mestrado) - Universidade de São Paulo, Piracicaba. https://doi. org/10.11606/D.11.2010.tde-17092010-181206

LOMBARDI NETO, F; BERTONI, J. (1975) Tolerância de perdas de terra para solos do estado de São Paulo. Campinas: Instituto Agronômico. 12 p.

MACEDO, F.L.; MÉLLO JÚNIOR, A.V.; MARCELLINI, S.S.; PEDROTTI, A. (2012) Modelagem da produção de sedimentos na sub-bacia hidrográfica do Riacho Jacaré-SE. RA'E GA, v. 24, p. 272-289. http:// doi.org/10.5380/raega.v24i0.26263

MANNIGEL, A.R.; CARVALHO, M.P.; MORETI, D.; MEDEIROS, L.R. (2002) Fator de erodibilidade e tolerância de perda dos solos para o estado de São Paulo. Acta Scientiarum, v. 24, n. 5, p. 1335-1340. https://doi.org/10.4025/actasciagron.v24iO.2374

MARQUES, J.J.G.S.M.; CURI, N.; FERREIRA, M.M.; LIMA, J.M.; SILVA, M.L.N.; CAROLINO DE SÁ, M.A. (1997) Adequação de métodos indiretos para a estimativa de erodiblidade de solos com horizonte B textural no Brasil. Revista Brasileira de Ciência do Solo, v. 21, n. 3, p. 447-456. http://doi.org/10.1590/S0100-06831997000300014

MIGUEL, P; DALMOLIN, R.S.D; PEDRON, F.A.; MOURA-BUENO, J.M.; TIECHER, T.(2014) Identificação defontes deprodução desedimentosem uma bacia hidrográfica de encosta. Revista Brasileira de Ciência do Solo, v.38, n. 2, p. 585-598. http://doi.org/10.1590/SO100-06832014000200023

MONDAL, A.; KHARE, D.; KUNDU, S. (2018) A comparative study of soil erosion modelling by MMF, USLE and RUSLE. Geocarto International, v. 33, n. 1, p. 89-103. https://doi.org/10.1080/10106049.2016.1232313

MOURA-BUENO, J.M.; DALMOLIN, R.S.D.; MIGUEL, P.; HORST, T.Z. (2018) Erosão em áreas de encosta com solos frágeis e sua relação com a cobertura do solo. Scientia Agraria, v. 19, n. 1, p. 102-112. http:// doi.org/10.5380/rsa.v19i1.53738

OCHOA, P.A.; FRIES, A.; MEJÍA, D.; BURNEO, J.I.; RUÍZ-SINOGA, J.D.; CERDA, A. (2016) Effects of climate, land cover and topography on soil erosion risk in a semiarid basin of the Andes. Catena, v. 140, p. 31-42. https://doi.org/10.1016/j.catena.2016.01.011

OLIVEIRA, P.T.S.; WENDLAND, E.; NEARING, M.A. (2O13) Rainfall erosivity in Brazil: A review. Catena, v. 100, p. 139-147. https://doi. org/10.1016/j.catena.2012.08.006

ORGANIZAÇÃO DAS NAÇÕES UNIDAS PARA A ALIMENTAÇÃO E A AGRICULTURA (FAO). (2O17) Soil Organic Carbon: the hidden potential. Roma: Organization of the United Nations.

OZCAN, A.U.; ERPUL, G.; BASARAN, M.; ERDOGAN, H.E. (2008) Use of USLE/GIS technology integrated with geostatistics to assess soil erosion risk in different land uses of Indagi Mountain Pass-Çankiri, Turkey. Environmental Geology, v. 53, n. 8, p. 1731-1741. https://doi. org/10.1007/s00254-007-0779-6 
PANAGOS, P.; BALLABIO, C.; LUGATO, E.; JONES, A.; BORRELLI, P. (2017) Condition of agricultural soil: factsheet on soil erosion. Luxembourg: EU Publication. https://doi.org/10.2760/728794

PRADO, J.P.B.; NÓBREGA, M.T. (2005) Determinação de perdas de solo na bacia hidrográfica do córrego Ipiranga em Cidade Gaúcha, Estado do Paraná, com aplicação da Equação Universal de Perdas de Solo (EUPS). Acta Scientiarum Technology, v. 27, n. 1, p. 33-42. https://doi.org/10.4025/actascitechnol.v27i1.1496

RENARD, K.G.; FOSTER, G.R.; WEESIES, G.A.; MCCOOL, D.K.; YODER, D.C. (1997) Predicting Soil Erosion by Water: A guide to conservation planning with the Revised Universal Soil Loss Equation (RUSLE). Estados Unidos: U.S. Department of Agriculture.

SANTOS, H.G.; JACOMINE, P.K.T.; ANJOS, L.H.C.; OLIVEIRA, V.A.; LUMBRERAS, J.F.; COELHO, M.R.; ALMEIDA, J.A.; ARAUJO FILHO, J.C.; OLIVEIRA, J.B.; CUNHA, T.J.F. et al. (2018) Sistema Brasileiro de Classificação de Solos. 5 a ed. Brasília: EMBRAPA. 590 p.

SANTOS, J.P. (2013) Erosividade determinada por desagregação de chuva diária no lado brasileiro da Bacia da Lagoa Mirim. 85f. Dissertação (Mestrado em Manejo e Conservação do Solo e da Água) - Faculdade de Agronomia Eliseu Maciel, Universidade Federal de Pelotas, Pelotas.

SCOPEL, l.; SOUSA, M.S.; MARTINS, A.P. (2013) Infiltração de água e potencial de uso de solos muito arenosos nos Cerrados (savanas) do Brasil. Boletim Goiano de Geografia, v. 33, n. 2, p. 45-61. https:// doi.org/10.5216/bgg.v33i2.25556

SILVA, F.G.B.; MINOTTI, R.T.; LOMBARDI NETO, F.; PRIMAVESI, O.; CRESTANA, S. (2010) Previsão de perda de solo na Fazenda Canchim-SP (EMBRAPA) utilizando geoprocessamento e o USLE 2D. Engenharia Sanitária e Ambiental, v. 15, n. 2, p. 141-148. https://doi. org/10.1590/S1413-41522010000200006
TIECHER, T.; MINELLA, J.P.G.; CANER, L.; EVRARD, O.; ZAFAR, M.; CAPOANE, V.; LE GALL, M.; SANTOS, D.R. (2017) Quantifying land use contributions to suspended sediment in a large cultivated catchment of Southern Brazil (Guaporé River, Rio Grande do Sul). Agriculture, Ecosystems \& Environment, v. 237, p. 95-108. https://doi. org/10.1016/j.agee.2016.12.004

TRINDADE, A.L.F.; OLIVEIRA, P.T.S.; ANACHE, J.A.A.; WENDLAND, E. (2016) Variabilidade espacial da erosividade das chuvas no Brasil. Pesquisa Agropecuária Brasileira, v. 51, n. 12, p. 1918-1928. https://doi. org/10.1590/sO100-204×2016001200002

TURMEL, M.S.; SPERATTI, A.; BAUDRON, F.; VERHULST, N.; GOVAERTS, B. (2015) Crop residue management and soil health: A systems analysis. Agricultural Systems, v. 134, p. 6-16. https://doi. org/10.1016/j.agsy.2014.05.009

WANG, X.; ZHAO, X.; ZHANG, Z.; YI, L.; ZUO, L.; WEN, Q.; LIU, F.; XU, J.; HU, S.; LIU, B. (2016) Assessment of soil erosion change and its relationships with landuse/cover change in China from the end of the 1980s to 2010. Catena, v. 137, p. 256-268. https://doi.org/10.1016/j. catena.2015.10.004

WISCHMEIER, W.H.; JOHNSON, C.B.; CROSS, B.V. (1971) Soil erodibility nomograph for farmland and construction sites. Journal of Soil and Water Conservation, v. 26, n. 5, p. 189-193.

WISCHMEIER, W.H.; SMITH, D.D. (1978) Predicting Rainfall Erosion Losses: A Guide to Conservation Planning. Washington, D.C.: United States Department of Agriculture. 58 p.

ZHOU, P.; LUUKKANEN, O.; TOKOLA, T.; NIEMINEN, J. (2008) Effect of vegetation cover on soil erosion in a mountainous watershed. Catena, v. 75, n. 3, p. 319-325. https://doi.org/10.1016/j. catena.2008.07.010 